\title{
Obesity and insulin resistance are significant predictors of serum leptin levels
}

To the Editor;

In the December 2016 issue of your journal, Fakor et al. (1) presented an original article entitled "The association between levels of maternal serum leptin in the third trimester and the occurrence of moderate preterm labor" in which the authors elucidated the possible role of leptin in the development of preterm labor in 30 moderate preterm delivering women. The authors demonstrated that low serum leptin levels may have a substantial predictive value for preterm birth before 34 weeks' gestation by altering cytokine balance, cytotrophoblast and angiogenic activity, in the feto-placento-maternal unit. Although the authors presented and discussed their study results effectively in the context of previous studies, we believe that like any other study, there are some methodologic issues related to the present paper. In this context, from a methodologic point of view, we have several concerns including unmatched body mass index (BMI) values of study participants, and the presence of a probable insulin resistance (IR), which is associated with preterm birth and serum leptin levels.

First, as also stated by the authors, numerous factors are strictly related with serum leptin levels including obesity, insulin, glucocorticoids, and thyroid hormones via multiple signaling pathways (2). From these variables, obesity presents a unique importance while evaluating serum leptin levels because of the fact that obese subjects have higher serum leptin values, which correlates body weight percentage, than normal weight subjects (3). The importance of BMI on serum leptin levels was demonstrated in a study by Paul et al. (4). Serum leptin levels and differences between sexes were found to be significant in all body mass indices. In this context, when comparing two groups to evaluate serum leptin levels, it is crucial to match study groups in respect to BMI values. The significantly higher BMI levels of control subjects $(p=0.017)$ could be the reason of elevated leptin levels. In order to rule out this bias, an additional statistical analysis is needed to understand if serum leptin levels are affected by the BMI values of study participants.
Second, although the authors stated that they excluded patients with diabetes mellitus, they gave no information about the possible presence of IR in their study group. IR is especially important for a study investigating a connection between leptin and preterm labor because IR contributes to the relatively wide variation in leptin levels, which is seen even at similar levels of body mass $(5,6)$. Moreover, IR below the thresholds of gestational diabetes mellitus (GDM) can cause adverse maternal and perinatal outcomes. In a recent large-scale retrospective study by Temming et al. (7), it was demonstrated that even in the absence of GDM, IR was associated with increased risks of preterm birth. Based on these data, it is reasonable to suggest that the alterations on serum leptin levels could be associated with IR and resulting preterm labor.

In conclusion, as we see an increasing number of obstetric complications including preterm labor, this study covers an important and interesting topic. We believe that the further understanding of the roles of adipocyte-derived hormones in human pregnancy will provide an insight into metabolic risks associated with preterm labor.

Fatma Beyazit, Mesut A. Ünsal

Department of Obstetrics and Gynecology, Çanakkale 18 Mart University Training and Research Hospital, Çanakkale, Turkey

\section{References}

1. Fakor F, Sharami SH, Milani F, Mirblouk F, Kazemi S, Pourmarzi D, et al. The association between level of maternal serum leptin in the third trimester and the occurrence of moderate preterm labor. J Turk Ger Gynecol Assoc 2016; 17: 182-5.

2. Janeckova R. The role of leptin in human physiology and pathophysiology. Physiol Res 2001; 50: 443-59.

3. Considine RV, Sinha MK, Heiman ML, Kriauciunas A, Stephens TW, Nyce MR, et al. Serum immunoreactive-leptin concentrations in normal-weight and obese humans. N Engl J Med 1996; 334: 292-5.

4. Paul RF, Hassan M, Nazar HS, Gillani S, Afzal N, Qayyum I. Effect of body mass index on serum leptin levels. J Ayub Med Coll Abbottabad 2011; 23: 40-3. 
5. Zuo H, Shi Z, Yuan B, Dai Y, Wu G, Hussain A. Association between serum leptin concentrations and insulin resistance: a populationbased study from China. PLoS One 2013; 8: e54615.

6. Zimmet PZ, Collins VR, de Courten MP, Hodge AM, Collier GR, Dowse GK, et al. Is there a relationship between leptin and insulin sensitivity independent of obesity? A population-based study in the
Indian Ocean nation of Mauritius. Mauritius NCD Study Group. Int J Obes Relat Metab Disord 1998; 22: 171-7.

7. Temming LA, Tuuli MG, Stout MJ, Macones GA, Cahill AG. Maternal and Perinatal Outcomes in Women with Insulin Resistance. Am J Perinatol 2016; 33: 776-80.

\section{Author's Response}

Dear Editor;

In a letter entitled "Obesity and insulin resistance are significant predictors of serum leptin levels," two main criticisms were mentioned. The first was the effect of body mass index (BMI) in leptin levels, which has been established in many previous studies $(1,2)$. We mentioned it in the introduction of the paper and also considered BMI as an important confounding variable in our study (3). As a basic study design concept, we tried to match BMI variables in the case and control groups. However, we could not select two BMI-matched groups $(p=0.017)$ because of the lack of patients with preterm labor. Therefore, we decided to decrease the effect of the BMI variable by statistical methods. The other criticism was the effect of insulin resistance (IR) on leptin level. As it was written in methods section of our article (3), we tried not to include conditions related with IR such as diabetes and polycystic ovarian syndrome. When patients are hospitalized in Iran, their blood sugar is checked as a routine lab test. In addition, a glucose tolerance test is performed between 24-28 weeks of pregnancy as a screening program in Iran.

Fereshteh Fakor', Seyedeh Hajar Sharami1 ${ }^{1}$, Forozan Milani ${ }^{1}$, Fariba Mirblouk1, Sodabeh Kazemi'1, Davoud Pourmarzi², Hannan Ebrahimi ${ }^{1}$, Seyedeh Fatemeh Dalil Heirati ${ }^{1}$

1Reproductive Health Research Center, Department of Obstetrics and Gynecology, Guilan University of Medical Sciences, Rasht, Iran

2Reproductive Health Research Center, Department of Epidemiology, Guilan University of Medical Sciences, Rasht, Iran

\section{References}

1. Paul RF, Hassan M, Nazar HS, Gillani S, Afzal N, Qayyum I. Effect of body mass index on serum leptin levels. J Ayub Med Coll Abbottabad 2011; 23: 40-3.

2. Considine RV, Sinha MK, Heiman ML, Kriauciunas A, Stephens TW, Nyce MR, et al. Serum immunoreactive-leptin concentrations in normal-weight and obese humans. N Engl J Med 1996; 334: 292-5.

3. Fakor F, Sharami SH, Milani F, Mirblouk F, Kazemi S, Pourmarzi D, et al. The association between level of maternal serum leptin in the third trimester and the occurrence of moderate preterm labor. J Turk Ger Gynecol Assoc 2016; 17: 182-5. 